\title{
Cuando la ciencia de la comunicación está implicada en la existencia del presente y la construcción del futuro'
}

\author{
Manuel Martín Serrano \\ (Universidad Complutense de Madrid)
}

Recibido: $6 / 3 / 2014$

Aprobado: 10/4/2014

\begin{abstract}
Resumen: El presente artículo tiene como propósito destacar el vínculo entre el trabajo científico y la liberación individual en el proceso de la renovación de la ciencia y de las tecnologías del futuro dentro de la comunicación. Dicha premisa enfatiza en la importancia de la investigación en el campo de las ciencias de la comunicación en la era actual. Asimismo, se explica la evolución de la libertad en los procesos de interacción social y las innovadoras formas de comunicación. Para un entendimiento más amplio del tema, se hace una recopilación de los puntos más importantes sobre teorías comunicativas y una comparación de la realidad de los imaginarios sociales entre América Latina y España.
\end{abstract}

Palabras clave: neoliberalismo / mediación social / teoría social / tecnología / progreso

\section{When communication science is involved in the existence of present and the building of future}

Summary: This article aims to emphasize the link between scientific work and individual liberation in the process of science renovation and future technologies in communication. This assumption emphasizes the importance of research in the field of Communication Sciences in the present era. Also, explains about the evolution of liberty in the processes of social interaction and the innovative ways of communication. For a broader understanding of the topic, it has been necessary a recompilation of the most important concepts about Communication theories and a comparison of the reality of the social imaginary between Latin America and Spain.

Key words: neoliberalism / social mediation / social theory / technology / progress

1 Difundido durante el homenaje que le dedicó la Facultad de Estudios Superiores Acatlán, de la Universidad Nacional Autónoma de México (UNAM). 
$\mathrm{P}$ rofesoras y profesores, alumnas y alumnos, que esperáis un relato basado en la experiencia personal, de cómo la comunicación ha encontrado su sitio entre los saberes científicos, permitidme que comience afirmando que la ciencia acertada se relaciona con la práctica justa.

\section{La ciencia acertada se relaciona con la práctica justa}

Es la creencia que compartíamos una generación de estudiantes que nos formamos en el bullir de los encuentros epistemológicos entre marxismo, existencialismo, psicoanálisis y estructuralismo. Movimientos de ideas que alcanzaron su clímax en Francia a finales de la década de los años sesenta. Visiones tan plurales del saber tenían en común el siguiente supuesto: los conocimientos teóricos tienen consecuencias prácticas, porque antes o después se aplican; ya sea para controlar, ya sea para emancipar a los seres humanos y sus sociedades.

Mostrar que la ciencia acertada se relaciona con la práctica justa es un criterio epistemológico y no solamente ético. Considero que esa percepción del vínculo entre trabajo científico y liberación individual y colectiva es un legado que tenemos que transmitir a quienes nos hereden. Ahora, cuando está en curso una de las renovaciones de las ciencias y de las tecnologías más determinante del futuro.
El vínculo que existe entre abrir los grados de libertad de las ciencias y ampliar las opciones de libertad real era una obviedad, al menos para quienes utilizábamos las nuevas metodologías (cibernética, análisis de sistemas) en el estudio de los comportamientos. Y la demostración de que tiene consecuencias prácticas utilizar el conocimiento que libera para criticar los usos de los conocimientos que oprimen se encuentra en la vida y milagros de la generación del 68. Las ideas sobre cómo cambiar las relaciones personales y sociales, que estaban en los libros de psicoanálisis y en los manuales de economía política, pasaron a la vida cotidiana. Proporcionaron razón y argumento a los movimientos juveniles. Inspiraron reivindicaciones que siguen vigentes. Una de ellas, que las revoluciones científico-técnicas se aplicasen a reducir las penurias y el embrutecimiento causados por la explotación económica. Y popularizaron diagnósticos de la frustración, que también son válidos. Por ejemplo, por qué y cómo la autorrepresión del gozo convertía a niños felices, creativos y tolerantes en adultos heridos, banales y agresivos. Aquel movimiento antirrepresivo (y, por consiguiente, antidepresivo) expresó su vitalidad en la forma lúdica que adoptaron las acciones juveniles cuando pararon la guerra de Vietnam, o cuando colocaron a la dictadura española frente a sus propios demonios.

Para asombro y desilusión de quienes creyeron que Mayo del 68 era el 
inicio de la revolución permanente, cinco años después - a partir de 1973 - se produjo la reconversión económica, cuyo desenlace sería la instauración del modelo llamado «neoliberal». El neoliberalismo completó, en apenas dos décadas, la entrega del control sobre los recursos materiales y sociales al capitalismo financiero, especulativo, por fin globalizado, es decir, monopólico e imperialista. Al mismo tiempo, consumó la mercantilización de la cultura y el control de la producción social de comunicación para el dominio. De esa inmersión en la cultura que des-ilustra no se ha salvado ninguna sociedad; lo mismo que de la codicia especulativa no se ha librado economía alguna.

Sin embargo, en España, las utopías de Mayo tuvieron una moratoria durante la década de los años setenta, porque estaban entreveradas con la transición política a la democracia. En concreto, la esperanza en el poder transformador de la producción/transmisión del conocimiento estaba renaciendo en la generación de profesores universitarios a la que yo pertenecía. Renacía un proyecto de «regeneración de la universidad», que diseñaron los intelectuales ilustrados cuando se instauró en España la República. Regeneración que consistía en vincular la teoría con la investigación y con la docencia; y todo ello, con la transformación de la sociedad. Este programa no se pudo llevar a término en España por la Guerra Civil. Pero se exilió a
México y encontró en la UNAM y en el Colegio de España (ahora de México) un nuevo destino. Medio siglo después - con la vuelta de la democracia a España-, tan noble concepto de la ocupación académica conservaba su valor (Martín, 2006).

La parte docente de esa regeneración quedó restablecida con la restauración de la democracia, porque ya se podía ejercer la enseñanza en libertad. Un logro que consumió gran parte del esfuerzo de los universitarios. Pero recuperar la libertad para hacer ciencia y docencia es la condición y no el fin de las regeneraciones académicas. El objetivo que teníamos en mente quienes veníamos del humanismo marxista era crear ciencia para la libertad. Una posibilidad poco frecuente que, sin embargo, a veces cabe llevar a cabo en algunos campos del conocimiento. $Y$ como aquí contaré, volvía a presentarse en la misma universidad en la que enseñaron los intelectuales republicanos, que era la mía.

«Ciencia para la libertad» puede ser una consigna acientífica, del mismo corte que «Ciencia para la salvación de las almas». Sin embargo, también es el enunciado que dio origen a las ciencias sociales. Había aparecido entre los enciclopedistas, para afirmar que el destino no estaba establecido por designios divinos y que los propios actores podían tomar en sus manos la conformación de su futuro personal y el de sus sociedades. Los fundadores de las ciencias sociales creyeron facti- 
ble orientar los descubrimientos científicos y sus aplicaciones técnicas a la construcción de nuevas sociedades donde vivir más libres y felices. Sociedades deseables, viables y necesarias; por lo tanto, históricamente previsibles. Es decir, han propuesto utopías, si recuperamos el valor ejemplar que tiene el recurso a estas fabulaciones (Martín, 1978). De hecho, las utopías ya han servido como guía de precedentes movimientos sociales. Bastará con recordar el papel que desempeñaron los programas enciclopedistas en la Revolución francesa.

Aquellos primeros científicos sociales sabían que las alternativas utópicas están constreñidas por organizaciones mentales e institucionales que tienen que ser desactivadas. Por eso los cambios históricos deseables requieren que exista la ciencia y no solamente la conciencia de la liberación. Llamaron "sociología» al estudio que servía para identificar la naturaleza y las causas de esos impedimentos, y para averiguar cómo podían ser removidos. Y los frankfurtianos restablecieron su dimensión «crítica» cuando el impulso liberador de la utopía embarrancó en el camino; toda vez que el conocimiento de cómo operan los impedimentos mentales e institucionales también se puede utilizar para reforzar los controles que dificultan la liberación. Se había aprendido, desde los primeros pasos de la Revolución francesa, que el uso de la Razón está condicionado por los intereses contrapuestos que se enfrentan en el seno de las sociedades. A partir de entonces y hasta ahora, parece que sin ciencias sociales puede existir la utopía, pero carente de la razón y del conocimiento que la hace realizable y, en ocasiones, de la eticidad que la hace deseable. Y resulta igual de cierto que sin pensamiento utópico cabe haber ciencia, pero no de los cambios sociales; se requiere de la perspectiva utópica que proporcione los escenarios donde representar las opciones - políticas, éticas, racionales- de la acción social.

El proyecto de hacer ciencia para la libertad en el espacio de la comunicación —que es donde está mi puesto académico- pudiera haber sido otra más de las iniciativas voluntaristas que desaparecieron en la vorágine neoliberal que, finalmente, penetraría en las universidades. Pero he podido continuar en ese propósito hasta ahora, porque la comunicación es actividad social indisociable de la construcción del presente y de la transformación del futuro. Y porque los estudios de la comunicación tienen fundamento científico. Según me parecía, y parece que, las ciencias de la comunicación pueden alcanzar la dimensión antropológica y la proyección histórica necesarias para mejorar nuestro destino.

\section{Latinoamérica en el imaginario y en el encuentro}

Cuando estaba en estos empeños, $L a$ mediación social comenzaba a tener una muy buena acogida en Latinoamérica. 
Con anterioridad, se empleaban otros textos míos, e incluso se los había reproducido para enseñar métodos de investigación. En cambio, este libro llegó a comienzos de los años ochenta, como una referencia epistemológica. En Latinoamérica hacía tiempo que se sabía, y se vivía, que para bien y para mal la comunicación pública orienta los cambios históricos. Esta perspectiva generaba la demanda de teorías «macro». Tal vez, esa era la utilidad que se le encuentra a La mediación social, que sirve para estudiar cómo se relacionan la comunicación, la acción social y la organización social (Martín, 2008)².

El Instituto de Cooperación con Iberoamérica (ICI) financió un evento en el que compartí visiones y trabajo con profesoras y profesores de Perú, Brasil, Colombia, Cuba, Ecuador, México, Puerto Rico; todas y todos relevantes personas $\mathrm{y}$, desde entonces, de mi mayor aprecio. Los resultados de esa reunión, que fue pionera, están publicados en un pequeño libro titulado La enseñanza de la comunicación en Latinoamérica. Otro fruto de aquel encuentro fue el comienzo de los cursos para profesores e investigadores latinoamericanos, que pusimos en marcha en mi Departamento desde 1982. Primero el ICI, más tarde el Ministerio de Educación y, con el tiempo, las ins- tituciones educativas de varios países de Latinoamérica, y ahora también de la Unión Europea, han proporcionado las becas. Esta fue la primera iniciativa que se llevó a cabo en España en el campo de la comunicación para abrir la universidad a ambos mundos. Es muy reconfortante que siga vigente.

Durante los años de lucha por las libertades, en España se había ido fraguando una imagen de Latinoamérica basada en la solidaridad frente a la opresión; leída en la novela, oída en la música, vista en la artesanía. Esa aproximación reverdecía el imaginario español, que siempre tuvo su principal referencia en la otra orilla. Y mi imaginario personal también tuvo que ver con esas iniciativas de encuentro. En la rama gallega de mi familia, se habían ido «a hacer las Américas», generación tras generación, una saga de antepasados que eran «los segundones» de un título nobiliario, por lo tanto, pobres y buscadores de honras, todos ellos perdidos en quién sabe qué vorágines desde Terranova a la Patagonia. Y mi mitología americana venía de tiempo atrás. Era estudiante cuando andaba interesado en el papel desempeñado por las utopías del Renacimiento en la primera emigración española al «Nuevo Mundo». Me fascinaron aquellos illuminati franciscanos, que huyeron desde Guadalajara

2 La mediación social (1986). Edición conmemorativa del 30 aniversario. Sobre el contenido y la influencia de esta obra, véase Publicaciones de Manuel Martín Serrano sobre mediaciones disponibles en E-Prints (E-Prints Complutense: http://eprints.ucm.es/13287/). 
(en Castilla) a la Nueva España, para buscar entre «los naturales» la pureza que no encontraban en sus paisanos oprimidos por credos, leyes y reyes; y sobre todo, el prometeico Vasco de Quiroga, que quiso probar que las tecnologías llevadas a México (de alfarería, metalurgia, carpintería, labranza) podían evitar la explotación, saciar los estómagos e incentivar y la creatividad de los pueblos indígenas. Fueron rusonianos antes que Rousseau, falansterianos antes que Fourier y waldenistas antes que Thoreau. Brevemente, han sido los primeros hombres de la Modernidad que se atrevieron a intentar realizar la utopía. Esos empeños y sus resultados son lecciones de la historia repletas de enseñanzas para las ciencias sociales, que vale la pena estudiar y no solo admirar.

La mediación social ha estado en el origen de una producción de escritos sobre mediaciones, en los cuales otros estudiosos proponen sus propios planteamientos y objetos de estudio. Es la utilización de una obra que más honra a su autor, porque la convierte en referencia paradigmática. El campo «mediación, comunicación, cultura, identidades», que comencé yo mismo cuando residía en Francia, se desarrolló en Latinoamérica; donde también se han realizado los trabajos más importantes sobre mediación y recepción. Del lado del mundo en el que yo resido, los análisis de las mediaciones se han aplicado sobre todo al papel que cumple en la producción y la reproducción (de las representaciones y las mentalidades, de los sistemas de comunicación, de las formaciones sociales).

\section{Cuando la comunicación encuentra su sitio en la historia y entre los saberes}

La comunicación tiene proyección histórica, puesto que está implicada en la existencia del presente y la construcción del futuro. Para explicar esa proyección hay que comenzar averiguando cómo se relacionan los cambios sociales con las innovaciones de los sistemas comunicativos. Así se identifican las etapas de la producción social de comunicación, desde sus orígenes asamblearios hasta las transformaciones virtuales que están en curso. En el libro que lleva ese título, se analizan tanto los factores socioeconómicos que han promovido las innovaciones tecnológicas de la comunicación, como la incidencia que dichas invenciones han tenido y tienen en la modificación de las sociedades (Martín, 1986)

Desde que aparece la imprenta, el desarrollo de las tecnologías comunicativas está vinculado con las formas

3 La producción social de comunicación (1986). Segunda edición española reformada y rescrita, y primera edición mexicana, 1993. Tercera edición revisada, 2004. 
de transformarse que tiene el capitalismo, transformando las sociedades. Tales relaciones son lo bastante determinantes como para identificar algunas leyes históricas, que están enunciadas y descritas en dicha obra. Por existir leyes que regulan las maneras en que las formaciones sociales incorporan las innovaciones comunicativas, puede existir una ciencia social de la comunicación. Tiene por objeto explicar cómo la comunicación pública participa en la reproducción y en el cambio de las sociedades.

Para interpretar cómo funcionan las interdependencias «comunicación» sociedad», cuando están institucionalizadas, hay que generar el correspondiente soporte teórico. En 1981, lo publiqué en Teoría de la comunicación. I. Epistemología y análisis de la referencia (conocido como «el libro blanco»). Un texto escrito con el propósito de que la teoría fuese materia enseñable (Martín, Piñuel, Gracia \& Arias, 1981) ${ }^{4}$. En «el libro blanco» expongo la teoría que concierne a aquellos sistemas comunicativos (SC) que están finalizados por las intervenciones de las organizaciones sociales (SS) y vinculados con los cambios de los universos referenciales (SR). Es una teoría social de la comunicación, que se refleja en el tan difundido «modelo dialéctico» (Martín, 1981).
En dicho libro reitero que los estudios comunicativos tendrían un lugar propio cuando exista de la teoría de la comunicación y no meramente sobre la comunicación. Cuando escribo estas líneas ya existe. Es específico de la teoría de la comunicación el campo de los comportamientos expresivos, o si se prefiere, indicativos, que son aquellos que hay que llevar a cabo para referirse a cuanto pueda ser mencionado. Pero quienes en aquellos tiempos se ocupasen de los fundamentos teóricos de la comunicación, recordarán que se vivía de prestado. La materia estaba troceada y en ocasiones disputada, entre múltiples perspectivas teóricas: informacionales, lingüísticas, cognitivas, estéticas, culturales, económicas y algunas más, todas ellas importantes y ninguna específica.

La teoría de la comunicación tiene su lugar en el espacio del conocimiento donde confluyen las ciencias de la vida y del hombre. Existía sobrada evidencia de que los comportamientos comunicativos son un palier, primero de la evolución natural y más tarde de las transformaciones sociales. A más abundamiento: en la comunicación humana las dimensiones naturales y culturales operan al tiempo. Ese traslado epistemológico requería la refundación teórica de los estudios de

4 Teoría de la comunicación. I. Epistemología y análisis de la referencia (1981). Segunda edición revisada y ampliada, 1982. Reimpresiones en España: 1983, 1985, 1988, 1989, 1991, 1993, 1995, 1997, 1999, 2002. Otras reimpresiones en América: México, Cuba, etcétera. 
la comunicación. Así era de fascinante el horizonte de creación científica que se ofrecía hacia 1980 en el campo de los estudios de la comunicación, a quienes tentase explorar territorios desconocidos.

\section{Para explicar cómo es posible que la comunicación sea posible}

Lo que seguía era desarrollar el trabajo teórico que estaba proponiendo. Había anticipado cómo pensaba que podía hacerse la refundación teórica de las ciencias de la comunicación en «el libro blanco». Lo cuento en el capítulo sobre los biologismos y los idealismos comunicativos. Ambos paradigmas son antropocéntricos, ya que establecen una divisoria infranqueable entre las capacidades humanas y animales. Pero el antropocentrismo había dejado de ser el fundamento de las ciencias del hombre, y ese derrumbe se llevaba por delante las teorías de la comunicación que habíamos recibido.

Mi propuesta para hacer teoría de la comunicación era que donde estaba el antropocentrismo estuviese la antropogénesis. La antropogénesis es el resultado de los procesos que nos han convertido en seres humanos. La humanidad se gestó en la evolución del medio natural $y$, desde que existe, continúa humanizándose con la transfor- mación de las sociedades. La comunicación es parte de esos procesos desde sus orígenes y lo seguirá siendo mientras que permanezca nuestra especie (Martín, 2009).

En 1982, comencé una obra en la que explicaba los orígenes de la comunicación, sus funciones evolutivas y las transformaciones que dieron lugar a la comunicación humana y, con ello, a la humanidad. Diez años más tarde, tenía escrito un texto que habría podido editar, si ya se hubiesen dado las condiciones científicas que hiciesen posible su validación. Había que esperar a que se cumpliese ese requisito, que era indispensable, ya que las teorías que se producen con criterios científicos tienen que ser verificables. Las ciencias de la vida y la paleontología aportaron la evidencia empírica y las metodologías que eran necesarias para poner a prueba esa propuesta teórica hace muy poco tiempo. Que fue cuando publiqué Teoría de la comunicación. La comunicación, la vida y la sociedad (2007). Es el libro en el que creo que puedo explicar cómo es posible que la comunicación sea posible (Martín, 2007)

Fundar la teoría de la comunicación en la antropogénesis es un giro científico, pero también axiológico. Proporciona bases objetivas a las éticas humanistas. En Teoría de la comunicación.

5 Sobre el contenido y la influencia de la teoría de la comunicación de Manuel Martín Serrano puede consultarse: http://eprints.ucm.es/13289/ 
La comunicación, la vida y la sociedad, se descubre que la solidaridad es un factor selectivo. Porque las comunidades que han llegado a ser humanas durante la evolución y han perdurado como tales se organizaron con base en el altruismo y el empeño en humanizar sus sociedades rigiéndose por valores. Este resultado desmiente la explicación del origen de la humanidad que comparten los darwinismos sociales, que se lo atribuyen al imperio de la ley de los más fuertes. Por lo que digo que la antropogénesis tiene una dimensión ética, la cual ha sido, desde siempre, el Humanismo.

La antropogénesis transforma el mundo para que nuestras sociedades permanezcan; y cambia nuestras sociedades para que el mundo perdure. Esa difícil forma de supervivencia ha funcionado hasta ahora, porque la comunicación mantiene el vínculo solidario entre ser en sí mismo y ser con los otros. En síntesis, la comunicación evolucionó como otra forma de asegurar la vida. La protección de aquellos que la naturaleza habría eliminado ha sido, en primera instancia, la razón por la que tenemos valores y cultura. Está explicado en el libro y espero haber sabido demostrarlo.

\section{Hacer ciencia de la comunicación cuando el mundo es referencia y la existencia se virtualiza}

El tenaz empeño puesto desde el siglo $\mathrm{XV}$ en utilizar la innovación comuni- cativa como instrumento del progreso humano alcanza en la actualidad sus objetivos. Ha llegado a término con la apropiación referencial del mundo, seguida por la virtualización de la existencia.

La apropiación referencial del mundo significa que cualquier persona puede tener noticia, en imágenes y sonidos y al momento, de cualquier cosa que exista o que pase en cualquier lugar. He denominado «índex» (en honor a Pierce) a los signos que reproducen imágenes perceptibles/audibles de lo que hay o acontece, al tiempo que existe o sucede, aquello a propósito de lo que se comunica.

La virtualización de la existencia consiste en que se puedan realizar en el espacio cibernético interacciones y actividades que anteriormente solo cabía llevar a cabo presencialmente, en el espacio real.

La comunicación referencial (en principio) abre un escenario donde lo que acontece puede ser conocido y comprendido sin depender del testimonio de los mediadores profesionales. Y la virtualización (en principio) aporta el acceso a las redes, la apertura a cualquier contenido, producible, reproducible, transformable, utilizable, por cuantas instituciones y personas sean virtualizables.

Comunicación referencial y virtual son invenciones relacionadas con dos utopías de «el Progreso»: la utopía del acceso universal a la información y la utopía del uso compartido del conocimiento. Fueron los iluministas quienes 
desde hace 250 años querían construir una sociedad del conocimiento, donde las tecnologías de la comunicación se utilicen para poner al alcance de todos la información que ilustra; que es aquella que saca de la ignorancia y del temor. Y fueron los fratelli quienes concibieron que la fraternidad se construya con el comunismo de las habilidades y conocimientos. Los fratelli transmitieron a los movimientos revolucionarios la visión de una sociedad en la que cada cual pusiese lo que sabía a disposición de todos los demás, y recibiese de los otros cuanto necesitase saber.

En resumen: comunicación referencial y virtual son tecnologías que pueden ser utilizadas para globalizar la ilustración y la solidaridad. Sin embargo, estas invenciones también sirven para usos que limitan e incluso invalidan las capacidades humanizadoras de «el progreso» comunicativo. Tal ambivalencia hace posible la aparición de visiones contrapuestas sobre el uso de las innovaciones tecnológicas, que se vienen enfrentando desde el principio de las revoluciones científico-técnicas. Por eso, al mismo tiempo que renacen las utopías, regresan las contrautopías.

El neoliberalismo ha recuperado la contrautopía tecnocrática. Es una concepción «del Progreso» que aparece con la Revolución Industrial. Considera necesario «desmontar» (ahora se dice «desconstruir») las utopías y la crítica social. Supuestamente, los avances tecnológicos realizan las primeras y cancelan la segunda; bastaría (dicen) que el funcionamiento de las sociedades se ajuste al de las tecnologías y no al revés. Es la expresión de la mitología burguesa de un mundo unificado por el mercado y controlado por las máquinas.

Nuevamente se pone en juego si el uso social del conocimiento y de las técnicas deberá de basarse en criterios antropológicos o instrumentales. Las operaciones mediadoras que promueven estos criterios contrapuestos se diferencian porque esclarecen $\mathrm{u}$ obscurecen los vínculos: los vínculos entre naturaleza y sociedad, entre el individuo y la comunidad, entre lo privado y lo público, de la creación y la coerción, de la comunicación respecto a la intervención. Finalmente, de la razón con la ética.

\section{Los caminos hacia la inacabada, inacabable, humanización de la sociedad}

Los iluministas valoraban el estado «de la Civilización», según el progreso hacia el humanismo. Creo que es esclarecedor continuar haciendo esa reflexión. Yo diría que la humanización se está integrando en el hacer de las ciencias y, en cambio, se va desincorporando cada vez más de las prácticas sociales. Lo primero afirma el avance de la razón y lo segundo, el poder de la explotación.

Cuando la sociedad entra en su cuarta revolución tecnológica, el pro- 
greso de conocimiento en numerosos campos irá al paso que marque el avance de la antropogénesis. Son las ciencias que se van haciendo al tiempo que se rehace una humanidad cada vez más humana. Y también es cuando instituciones que informan y socializan, controladas por poderes políticamente opresivos y económicamente desalmados, están utilizando las capacidades que ofrecen las tecnologías para la comunicación mediada, en contra de la utilización social del conocimiento que ilustra y emancipa.

Los científicos, en general, y los científicos sociales, en particular, podemos continuar con la tarea de ilustrar contribuyendo a que sean visibles tales utilizaciones; y sus causas, comprensibles. Ilustrar es hacer saber las ambivalentes capacidades que tienen los actuales sistemas informativos y comunicativos desde que existen las tecnologías referenciales y virtuales. Hacer saber que lo que se haga con la comunicación, y desde la comunicación, contribuirá en mucho a la realización de las dos utopías del humanismo — «iluminista» y «comunista»-, sin duda las más nobles que nos ha propuesto la Modernidad. E ilustrar es hacer saber que también es el tiempo de las mediaciones comunicativas contrautópicas. Cuando en la comunicación pública se difunde más banalidad que conocimiento, más desinformación que información; se contribuye más a la violencia que a la tolerancia, más a la sumisión que a la liberación.
Las mediaciones comunicativas contrautópicas utilizan las acrecentadas capacidades de los sistemas de comunicación para reforzar controles cognitivos y culturales que esos mismos progresos hacen innecesarios. Desprovistas de humanismo, inundan la cotidianeidad de conflictos y derrotas que globalizan la infelicidad. Insolidarias, alimentan prejuicios y estereotipos que vinculan la seguridad individual y colectiva al etnocentrismo, la xenofobia. Pero, sobre todo, son las mediaciones que legitiman la barbarie globalizada, cuyas señas son la imposición de la fuerza, la destrucción de recursos naturales y culturales.

La comunicación ha llegado al estadio en el que la solidaridad con quienes han de sucedernos es criterio de racionalidad; toda vez que la aplicación que desde ahora se está haciendo de las TIC condiciona la existencia de las futuras generaciones. Es uno de los ámbitos en donde se ha hecho evidente que la teoría acertada se relaciona con la práctica justa. Se trata de un acontecimiento histórico, y además epistemológico, que se estaba esperando desde hace más de dos siglos. Desde que Kant estableció el humanismo como criterio de razón (además de ético) para orientar las acciones y las relaciones colectivas. Criterio mantenido por los herederos de las «críticas» kantianas de la razón y de las costumbres. Que son quienes están en el empeño de esclarecer/reconstruir lo que la racionalidad instrumental —que nos 
utiliza como meras cosas- oscurece/ desconstruye. Son quienes indagan la razón y la sinrazón de nuestro modo de producir y de reproducir a los sujetos, a las comunidades, a sus bienes materiales y simbólicos. Las cuestiones que, en mi opinión, despejan los caminos hacia la inacabada, inacabable, humanización de la sociedad.

La historia ha dejado constancia, hasta ahora, de que la humanidad acaba incorporando en su existencia cotidiana el potencial humanizador de las innovaciones comunicativas. En todo caso, esa incorporación no se ha completado en tanto que detentaron el poder las instituciones que lo impedían. Recuérdese que hicieron falta más de cuatro siglos de revoluciones burguesas para liberar el acceso a la información y al conocimiento que permitía la imprenta. Puede suceder que los cambios históricos relacionados con la utilización social de la comunicación referencial y virtualizada requieran, en esta ocasión, plazos menos largos. Aunque, en nuestro tiempo, esas innovaciones estén contribuyendo al dominio - tan rápido y global- del capital financiero, especulativo y militarista. Pero tan excepcional expansión puede ser, paradójicamente, signo de que el colapso de este sistema político llegará en menos tiempo que el de los regímenes que le han precedido. He mostrado que cuanto más de- pende el funcionamiento del régimen vigente del recurso a la forma actual de producir y utilizar el conocimiento y la información, tanto más se amplifican las contradicciones (Martín, 2004). Aunque sería insensato olvidar que el desorden que está generando el denominado «nuevo orden mundial» puede llegar a tener tal magnitud que sumerja a la humanidad en otra larguísima edad media. En este escenario, hacer ciencia es, como siempre ha sido, poner la razón donde reine la ignorancia. Y, además, es armar de razón a las sociedades para enfrentarse contra las fuerzas ciegas y sordas, pero poderosas además de ignorantes, que pueden destruirlo todo.

Profesores, profesoras, alumnos y alumnas, que me habéis acompañado hasta este punto final:

Ahora sabéis por qué escribo que nuestro tiempo es el tiempo de hacer ciencia para la libertad; por qué la procuro y cómo contribuye a la humanización. Comprobáis que la teoría proporciona soporte racional a la conciencia social, cuando puede devolver, renovada y confirmada científicamente, la convicción ética que dio origen a las utopías todavía vigentes: que la humanidad aparece y se perpetúa cuando la libertad individual y la solidaridad colectiva son conciliables.

Con todo mi aprecio. 


\section{Referencias}

Martín Serrano, M. (1978). Introducción del libro Métodos actuales de investigación social. En M. Martín Serrano. Métodos actuales de investigación social (pp. 7-11). Madrid: Akal. Disponible en http://eprints.ucm.es/13146/

Martín Serrano, M. (1981). El modelo dialéctico de la comunicación. En M. Martín Serrano, J. L. Piñuel, J. Gracia, \& M. A. Arias. Teoría de la comunicación. I. Epistemología y análisis de la referencia (pp. 159-174). Madrid: A. Corazón. Disponible en http://eprints.ucm.es/13116

Martín Serrano, M., Piñuel, J. L., Gracia, J., \& Arias, M. A. (1981). Teoría de la comunicación. I. Epistemología y análisis de la referencia. Madrid: A. Corazón (Ed.).

Martín Serrano, M. (1986). La producción social de comunicación. Madrid: Alianza Editorial.
Martín Serrano, M. (2004). La forma vigente de producir comunicación pública. Desarrollo y quiebra. En M. Martín Serrano. La producción social de la comunicación (pp. 120125). Disponible en http://eprints. ucm.es/13239/

Martín Serrano, M. (2006). La vocación de la sociología académica española. Desde el tiempo de las utopías al de la contrautopía. Revista Española de Sociología, 6, 107-113. Disponible en http://www.fes-web.org/publicaciones/res/archivos/res06/06.pdf

Martín Serrano, M. (2007). Teoría de la comunicación. La comunicación, la vida y la sociedad. Madrid: McGrawHill, Interamericana de España.

Martín Serrano, M. (2008) [1977]. La mediación social. Madrid: Akal.

Martín Serrano, M. (2009). La comunicación en la existencia de la humanidad y de sus sociedades. Revista MATRIZes, 3 (1), 1-8. Disponible en http:// eprints.ucm.es/13112/ 